\title{
Solution-processed nickel oxide films and their liquefied petroleum gas sensing activity
}

\author{
Sandesh U. Mutkule, ${ }^{\mathrm{a}, \mathrm{b}}$ Sachin T. Navale, ${ }^{\mathrm{c}}$ V. V. Jadhav, ${ }^{\mathrm{b}}$ Swapnil B. Ambade, ${ }^{\mathrm{d}}$ Mu. Naushad, ${ }^{\mathrm{e}}$ \\ Ashok D. Sagar, ${ }^{a}$ Vikas B. Patil, ${ }^{f}$ Florian J. Stadler ${ }^{\mathrm{c}, *}$, and Rajaram S. Mane, ${ }^{\mathrm{b}, \mathrm{e}, *}$ \\ ${ }^{a}$ School of Chemical Sciences, Swami Ramanand Teerth Marathwada University, Nanded, \\ 431606, India \\ ${ }^{\mathrm{b}}$ Centre for Nanomaterials \& Energy Devices, Swami Ramanand Teerth Marathwada \\ University, Nanded, 431606, India \\ ${ }^{c}$ College of Materials Science and Engineering, Shenzhen Key Laboratory of Polymer Science \\ and Technology, Guangdong Research Center for Interfacial Engineering of Functional \\ Materials, Nanshan District Key Lab for Biopolymers and Safety Evaluation, Shenzhen \\ University, Shenzhen 518060, PR China \\ ${ }^{\mathrm{d}}$ School of Semiconductor and Chemical Engineering, Chonbuk National University, 664-14, \\ 1-ga Deokjin-dong, Deokjin-gu, Jeonju, Jeonbuk, 561-756, Republic of Korea \\ ${ }^{e}$ Department of Chemistry, College of Science, Bld\#5, King Saud University, Riyadh, Saudi \\ Arabia \\ ${ }^{\mathrm{f}}$ Functional Materials Research Laboratory, School of Physical Sciences, Solapur University, \\ Solapur - 413255, M.S., India
}

\begin{abstract}
Present article demonstrates the facial synthesis of nickel oxide (NiO) films via an easy and costeffective successive ionic layer adsorption and reaction (SILAR) method onto glass substrate using nickel (II) chloride as precursor and their gas sensing activity towards different target gases. Structural elucidation and elemental composition analysis measurements were conducted using X-ray diffraction, Raman and energy dispersive X-ray techniques, respectively. Platelettype morphology was confirmed from the plane-view images recorded on field-emission scanning electron and transmission electron microscopes at different magnifications. Chemoresistive performance of $\mathrm{NiO}$ films was carried out towards hazardous and explosive gases such as ammonia, methanol, ethanol, liquefied petroleum gas (LPG) and nitrogen dioxide as a function of working temperature and gas concentration. Amongst diverse gases, $\mathrm{NiO}$ sensor film
\end{abstract}


exhibits better response of $72 \%$ to 5000 ppm LPG at lower operating temperature $\left(180{ }^{\circ} \mathrm{C}\right)$. Effect of LPG concentration on gas response of the $\mathrm{NiO}$ film was systematically investigated and explored. Also, the synergistic interaction between LPG molecules and NiO nanoplates was studied and explored using potential barrier model.

Keywords: Nickel oxide; SILAR, Gas Sensing properties; Response-recovery; Modeling

*Corresponding authors. Emails: rsmane_2000@yahoo.com, Tel: +919850331971, Fax: +912462229574 (Rajaram S. Mane, Prof.), fjstadler@szu.edu.cn, Tel: +86-0755-26538236, Fax: +86-0755-26536239 (Florian J. Stadler, Prof.).

\section{Introduction}

The importance of gas sensor as the low-cost and environmentally friendly technology is prompting researchers to seriously consider industrial and domestic safety [1,2]. Liquefied petroleum gas (LPG) is one of the perilous combatable gases because leaks can lead to serious accidents. Therefore, development of sensing materials detecting hazardous LPG gas at low ppm level is essential. Alternatively, nitrogen dioxide $\left(\mathrm{NO}_{2}\right)$ above its $100 \mathrm{ppm}$ level can cause death due to asphyxiation from fluid in the lungs and 25 and $30 \mathrm{ppm}$ levels of ammonium $\left(\mathrm{NH}_{3}\right)$ are respectively detected simply by smelling and reasonable for feeling uncomfortable for human beings. The comprehension of these goals is unfeasible without taking the importance of the materials like transition metals/metal oxides into account, so the focus on the preparation and deposition methods is vital. These methods can be either physical or chemical in the form of powders or thin layers (on an appropriate substrate). Metal oxide chemical bath deposited thin films composed of nanoparticles such as $\mathrm{ZnO}, \mathrm{SnO}_{2}, \mathrm{Fe}_{2} \mathrm{O}_{3}, \mathrm{In}_{2} \mathrm{O}_{3}, \mathrm{TiO}_{2}$ etc., are attractive for the development of gas sensing devices owing to their obvious advantages such as low production-cost as well as conservable thermal and chemical stabilities [2-13]. In addition, transition metal oxide nanostructures with altered surface morphologies can be excellent for the manufacture of the gas sensor devices. It is accepted that the conductivity of transition metal oxide nanostructures can be tuned with the surface desorption and adsorption of gas molecules. This change is mainly caused by the electronic transfer that occurs upon the adsorption of gas molecules over the surface of film. Conductivity changes robustly depending upon the shape and the size of the nanostructures used [5-7]. Among various transition metal oxides, nickel oxide 
(NiO) is a promising metal oxide with a wide band gap of 3.6-4.0 eV and acts as a $p$-type semiconductor, which finds numerous applications in smart windows [8], electrochemical supercapacitors [9-11], as a transparent $p$-type semiconducting layer [12, 13], as an antiferromagnetic film [14], and in dye sensitized solar cells (as a photocathode) too [15]. It exhibits anodic electrochemical stability, excellent durability, large spin optical density, and various manufacturing possibilities. Nowadays, plethora of $\mathrm{NiO}$ semiconductor nanostructures is a hot topic in the new era of gas sensor research. Different methods have been reported for the synthesis of $\mathrm{NiO}$ nanoparticles such as thermal evaporation [16, 17], magnetron sputtering [1819], electrodepositon [20], sol-gel [21], chemical bath deposition (CBD) [10], successive ionic layer adsorption and reaction (SILAR) method, spray pyrolysis [22], surfactant mediated synthesis [23], polymer matrix-assisted synthesis [24], thermal decompositions [25], microemulsion [26], etc. Of these, SILAR is one of the prominent methods because of its simplicity and inexpensive way of deposition of variety of metal oxides in the form of thin films. In this method, a uniform thin film of nanoparticles is obtained through layer-by-layer approach on the substrate surface. Advantages of this method include simple operation, cheap, highly efficient and thickness controllability of the deposited film [27] etc. The gas sensing performance can be improved by understanding the influence of size, porosity, and morphology of the nanostructure [3-5]. Nanoparticles, on account of their sizes, exhibit novel material properties that are significantly different from those of their bulk counterparts. $\mathrm{NiO}$ nanoparticles of equal dimensions and good dispersion are desirable for many applications e.g. in designing ceramic, magnetic, electro-chromic, and heterogeneous catalytic [24-29] etc. Gunjakar et al. [30] reported LPG sensor-based on chemical bath deposited $\mathrm{NiO}$ thin films operating at $698 \mathrm{~K}$ with a response of 36.5\% and in a second report, Nalage et al. [31] developed sol-gel-based NiO thin film sensor with $23.3 \%$ response for the detection of $\mathrm{NO}_{2}$ gas at $200^{\circ} \mathrm{C}$. Recently, Dalavi et al. [32] reported nanoporous network of $\mathrm{NiO}$ using CBD method and applied for $\mathrm{NH}_{3}$ gas with $13 \%$ response at $250{ }^{\circ} \mathrm{C}$. In short, depending upon the nature of conductivity i.e. $n / p$-type, type of nanostructure, porosity and crystal structure of thin/thick metal oxide/polymer films and type of gas used for detection have strong influence of sensor application.

Herein, we demonstrate the synthesis of $\mathrm{NiO}$ films by a facile SILAR method approach at room temperature $\left(25^{\circ} \mathrm{C}\right)$ without the necessity of any surfactant and later used for the detection of hazardous LPG at lower temperature. As-deposited NiO film was characterized for its structural, 
morphological, and surface related properties and then studied its sensing properties, which shows an excellent response of $72 \%$ towards $5000 \mathrm{ppm}$ exposure of LPG gas. The obtained results of NiO sensor film for LPG constitute a significant improvement of reports in literature [30-32].

\section{Experimental details}

\subsection{Synthesis of $\mathrm{NiO}$ film}

Analytical reagent grade (AR) chemicals such as $\left(\mathrm{NiCl}_{2}\right) \cdot 6 \mathrm{H}_{2} \mathrm{O}$, and ammonia $\left(\mathrm{NH}_{4} \mathrm{OH}\right)$ were used for synthesis of nickel oxide. Before the deposition of $\mathrm{NiO}$ thin films, glass slides were cleaned with detergent and double distilled water, then boiled in chromic acid $(0.5 \mathrm{M})$ for 15 min, and then were washed with double-distilled water and ultrasonicated for $15 \mathrm{~min}$. Finally, these slides were degreased in AR grade acetone and used for deposition. To obtain good quality $\mathrm{NiO}$ thin film; adsorption, reaction and rinsing time durations were controlled correctly and carefully. The film was deposited as a complete film layer with experimental conditions-like $\mathrm{p}^{\mathrm{H}}$, concentration and temperature of cationic and anionic precursor solutions. One cycle of $\mathrm{Ni}(\mathrm{OH})_{2}$ film was composed of combination of two half cycles; first half was immersion of glass slide in nickel precursor solution maintained at $\mathrm{pH} \approx 12$ for $25 \mathrm{~s}$ followed rinsing in water $20 \mathrm{~s}$ and second half was in hot water maintained at $90^{\circ} \mathrm{C}$ for $20 \mathrm{~s}$. It was observed that $\mathrm{NiO}$ film deposited onto glass slide using SILAR method was gray in appearance, uniform and welladherent to the glass substrate. Additionally, we performed the same kind of synthesis with 30 cycles to visualize the film. Moreover, it would be pointed out that the initial growth of $\mathrm{Ni}(\mathrm{OH})_{2}$ was limited, however, as the nucleation rate was considerably high. The deposited films of $\mathrm{Ni}$ $(\mathrm{OH})_{2}$ were annealed at $573 \mathrm{~K}$ for $1 \mathrm{~h}$ in order to form $\mathrm{NiO}$, which was qualitatively confirmed as the surface appearance was changed from faint greenish to dark black (Fig.1).

\subsection{Material characteristics}

X-ray diffraction (XRD) pattern of $\mathrm{NiO}$ film was recorded using Rigaku D/MAX 2500V

diffractometer using $\mathrm{Cu}-\mathrm{K}_{\alpha}$ radiation (source of X-ray). Wavelength of source was $1.5418 \AA$ and operating conditions were; $40 \mathrm{kV}, 60 \mathrm{~mA}, 10^{\circ}-80^{\circ}$ (20) scanning angle range and $0.03^{\circ} / \mathrm{s}$ scanning rate. The microstructure of the $\mathrm{NiO}$ sample was analyzed by field-emission scanning 
electron microscopy (Model: FESEM, Hitachi S-4200). The atomic concentrations of carbon, oxygen, and nickel were determined by energy dispersive X-ray spectrometer (EDX). The highresolution transmission electron microscopy (HRTEM) and selected area electron diffraction (SEAD) measurements were carried out by using FEI TECNAI G2 S-TWIN instruments equipped with $\mathrm{LaB}_{6}$ cathode and a GATAN MS794 P CCD camera. The micrographs were obtained at an acceleration voltage of $200 \mathrm{kV}$.

\subsection{Sensor properties}

Chemiresistive performance of $\mathrm{NiO}$ sensor film, composed of upright-standing nanoplates, was monitored by using home built static gas sensing unit. For the measurement of change in film resistance, two silver contacts separated from each other by $1 \mathrm{~cm}$ were drawn on the film and dried at air atmosphere before measurement. Concentration of several gases such as ammonia $\left(\mathrm{NH}_{3}\right)$, methanol $\left(\mathrm{CH}_{3} \mathrm{OH}\right)$, ethanol $\left(\mathrm{C}_{2} \mathrm{H}_{5} \mathrm{OH}\right)$, nitrogen dioxide $\left(\mathrm{NO}_{2}\right)$, and LPG (propane + butane) in the air-tight chamber was achieved by injecting a defined amount by a syringe. All gases used for the study were in the form of canisters with $40000 \mathrm{ppm}$ concentration. The measurement of resistance was carried out in presence of air and gas atmosphere as a function of temperature (in increment of $10^{\circ} \mathrm{C}$ ). Temperature of the sensor was controlled with the help of digital temperature controller of the sensing unit, which can heat from room temperature to 500 ${ }^{\circ} \mathrm{C}$. For the gas sensing measurements, sensor film was mounted in an air-tight glass chamber with a volume of $500 \mathrm{~cm}^{3}$. The changes in resistances of the $\mathrm{NiO}$ sensors due to the presence of LPG and $\mathrm{NH}_{3}, \mathrm{CH}_{3} \mathrm{OH}, \mathrm{C}_{2} \mathrm{H}_{5} \mathrm{OH}$, and $\mathrm{NO}_{2}$ gases were noted and plotted as function of time. The response $(\%)$ was calculated using the following relation;

$$
\text { Response (S) (\%) }=\left[\mid \mathrm{R}_{\mathrm{g}}-\mathrm{R}_{\mathrm{a}} / \mathrm{R}_{\mathrm{a}}\right]^{*} 100
$$

where, $R_{g}$ and $R_{a}$ are the resistances of $\mathrm{NiO}$ film in gas and air, respectively. The gas concentration of in ppm was calculated by the following formula:

Concentration in ppm of test gas $=[$ Volume of gas in $\mathrm{ml} . \mathrm{x}$ Conc. of gas in cylinder $/$ Volume of

Chamber] 


\section{Results and discussion}

\subsection{NiO film formation mechanism}

Films of $\mathrm{Ni}(\mathrm{OH})_{2}$ were initially obtained by immersing ultrasonically cleaned glass slides into separately placed cationic and anionic precursors i.e. $\mathrm{NiCl}_{2}$ and water. Initially, $0.1 \mathrm{M} \mathrm{NiCl}_{2}$ was used as a source of nickel and ammonia $\left(\mathrm{NH}_{4} \mathrm{OH}\right)$ solution $(25 \%$ extra pure) was added with constant stirring to make it alkaline $(\mathrm{pH} \approx 12)$. The growth of a thin film deposition process is of the ion-by-ion type by surface coagulation and adsorption of collides at the nucleation sites [3234]. When aqueous ammonia solution was added to nickel chloride, the ionic product of $\mathrm{Ni}(\mathrm{OH})_{2}$ exceeds the solubility product and the solution becomes turbid due to formation of Ni- $(\mathrm{OH})_{2}$ precipitates. We believed that at higher $\mathrm{pH}$, solution attains supersaturaion thereby ions find considerably higher energy and fast rate of reaction by loosing $\mathrm{OH}^{-}$ions whereas at lower ${ }_{\mathrm{p}}{ }^{\mathrm{H}}$ ions are bound and reaction kinetics is relatively slow.

$$
\mathrm{NiCl}_{2}+2 \mathrm{NH}_{4} \mathrm{OH} \longrightarrow \mathrm{Ni}(\mathrm{OH})_{2}+2 \mathrm{NH}_{4}^{+}+2 \mathrm{Cl}^{-}
$$

However, excess addition of surplus ammonia solution reduces $\mathrm{Ni}_{2}{ }^{+}$ion by producing the complex with coordination number four. This can be explained by the following reaction;

$$
\mathrm{Ni}(\mathrm{OH})_{2}+4 \mathrm{NH}_{4}^{+} \longrightarrow \mathrm{Ni}\left(\mathrm{NH}_{3}\right)_{4}^{2+}+2 \mathrm{H}_{2} \mathrm{O}+2 \mathrm{H}^{+}
$$

The triple distilled water provides source of $\mathrm{OH}^{-}$ions by heating at the temperature near boiling point $\left(90^{\circ} \mathrm{C}\right)$. When glass slide is immersed in the above solution, the force of attraction between nickel (complex) ions and the substrate leads to their adsorption on the surface eventually making the film adherent.

$$
\begin{aligned}
\mathrm{Ni}\left(\mathrm{NH}_{3}\right)_{4}{ }^{2+}+2 \mathrm{OH}^{-} & \longrightarrow \mathrm{Ni}(\mathrm{OH})_{2} \\
\mathrm{Ni}(\mathrm{OH})_{2} & \stackrel{\Delta}{\longrightarrow} \mathrm{NiO}
\end{aligned}
$$




\subsection{Structural elucidation}

The XRD pattern of $\mathrm{NiO}$ film, as seen in Fig. 2(a) shows the $\mathrm{NiO}$ deposited onto a glass slide was perfectly crystalline and pure. XRD spectrum of NiO showed Braggs reflections at $2 \theta=$ $37.28^{\circ}, 43.31^{\circ}, 62.54^{\circ}$ and $75.46^{\circ}$, which were assigned to the scattering from (111), (200), (220) and (311) planes of cubic NiO respectively. All the diffraction peaks agreed closely with JCPDS file no. 47-1049 (cubic nickel oxide (bunsenite, $\mathrm{NaCl}$ type structure)). No other noticeable impurity peaks were detected in XRD analysis, suggesting purity in structure and phase of NiO. The presence of sharp diffraction peaks was an indication of the polycrystalline nature of the synthesized $\mathrm{NiO}$ [35]. The formation of $\mathrm{NiO}$ was also evident from the Raman spectrum (Fig. 2(b)) carried out on thin films of NiO formed by SILAR method. Raman spectrum of $\mathrm{NiO}$ illustrates two vibrational bands centered at $550 \mathrm{~cm}^{-1}$ and $1095 \mathrm{~cm}^{-1}$, which were due to one phonon (1P) longitudinal optical (LO) and 2LO modes of Ni-O oscillation, respectively $[36,37]$.

\subsection{Surface appearance}

The microstructure of $\mathrm{NiO}$ film was analyzed from digital photo-image obtained using FESEM (Fig.3 (a), (b) and (c) at $1 \mu \mathrm{m}, 600 \mathrm{~nm}$ and $300 \mathrm{~nm}$ ). FESEM image confirmed mixed and irregular platelet-type surface morphology of NiO. Such porous-type morphology could be beneficial for gas sensing application due to offerings of large specific surface area to effect elevated response of the target gas (herein LPG). It was interesting to see particles in agglomerated form that could be detrimental in gaining the expected responsively; however, because of high surface area sufficient amounts of active sites for gas adsorption could present. We believe that gas circulation occurred more readily due to nanoplate-type morphology and porous structure, which might promote the reaction between film surface and gas molecules by resulting higher response [38]. The EDX analysis (Fig. 3(d)) was carried out to identify the presence of nickel and oxygen in chemically deposited $\mathrm{NiO}$ film with reference peak at $0 \mathrm{keV}$. EDX spectrum clearly presents the existence of $\mathrm{Ni}$ and $\mathrm{O}$ elements in the deposited film with stoichiometry of 54:46 (Ni:O). The HRTEM image (Fig.4 (a)) and TEM image (Fig.4 (b\&c)) confirmed NiO NPs with size ranging 4-8 $\mathrm{nm}$ in the near surface of copper grew. The high 
resolution TEM (Fig. 4(a)) proved lattice arrangement and pure crystallinity. SEAD pattern (Fig.4 (d)) demonstrates NiO NPs were perfectly crystalline in nature with peaks (111), (200), (220) and (311).

\subsection{Gas sensing studies}

Gas sensing characteristics of SILAR deposited $\mathrm{NiO}$ sensor films were studied towards various oxidizing and reducing gases such as $\mathrm{NH}_{3}, \mathrm{CH}_{3} \mathrm{OH}, \mathrm{C}_{2} \mathrm{H}_{5} \mathrm{OH}$, LPG and $\mathrm{NO}_{2}$ using the above described two-probe home built gas sensor unit. It is well-known that the sensing material exhibits a maximum response towards a target gas at a particular temperature - termed optimized temperature. So, by setting the temperature one can exploit the sensor for the particular gas recognition. Therefore, initially sensing performance of $\mathrm{NiO}$ film was carried out with respect to temperature to $5000 \mathrm{ppm}$ LPG as a target gas and the equivalent results are displayed in Fig. 5(a). The NiO film sensor demonstrated a maximum response of $72 \%$ to $5000 \mathrm{ppm} \mathrm{LPG} \mathrm{gas} \mathrm{at}$ $180{ }^{\circ} \mathrm{C}$. LPG gas molecules should have adequate thermal excitation energies to respond to adsorbed oxygen species at $180{ }^{\circ} \mathrm{C}$; therefore, at this temperature $\mathrm{NiO}$ sensor reached maximum value of its response. Hence, for further sensing study $180^{\circ} \mathrm{C}$ was used as optimized value of temperature. Selectivity is an essential constraint of gas sensor and it is the ability of sensor response to target gas in the presence of other test gases. Fig. 5(b) shows selectivity bar chart of $\mathrm{NiO}$ sensor for each gas having $500 \mathrm{ppm}$ concentration and operating at $180{ }^{\circ} \mathrm{C}$. Selectivity study clearly demonstrates that the sensor material based on $\mathrm{NiO}$ was quite sensitive and selective towards LPG gas ( $35 \%$ response to $500 \mathrm{ppm}$ ). Upon the interaction of oxidizing gases (herein $\mathrm{NO}_{2}$ ), electron accepting in nature, the resistance value of $\mathrm{NiO}$ sensor found to be decreasing. In contrast, for reducing gases $\left(\mathrm{NH}_{3}, \mathrm{CH}_{3} \mathrm{OH}, \mathrm{C}_{2} \mathrm{H}_{5} \mathrm{OH}\right.$, and $\left.\mathrm{LPG}\right)$, electron donating in nature, is found to be increasing. Therefore, the response value for $\mathrm{NO}_{2}$ shown towards the opposite direction than that of reducing gases in the selectivity bar chart is due its characteristic features. Higher response to LPG is due to the more rate of interaction of LPG molecules with $\mathrm{NiO}$ sensor surface as compared to other target gases. In addition various gases have diverse energies for reaction to take place on the sensor surface. Besides, much lower responses were obtained for $\mathrm{NH}_{3}, \mathrm{CH}_{3} \mathrm{OH}, \mathrm{C}_{2} \mathrm{H}_{5} \mathrm{OH}$ and $\mathrm{NO}_{2}$ gases compared to $\mathrm{LPG}$ gas, indicating that the $\mathrm{NiO}$ sensor has a better selectivity to LPG. It is well-known that, diverse gases possess diverse energies for adsorption, desorption and reaction on the surface of metal oxide. In present case, 
rate of reaction between LPG molecules and surface of $\mathrm{NiO}$ could be greater; hence sensor exhibited utmost selectivity to LPG compared to other trial gases. Moreover, selective coefficient (K) was calculated using the following relation [36] and obtained results are tabulated in Table 1.

$$
\mathrm{K}=\mathrm{S}_{\mathrm{A}} / \mathrm{S}_{\mathrm{B}}
$$

where $\mathrm{S}_{\mathrm{A}}=$ Response to $\mathrm{LPG}$ and $\mathrm{S}_{\mathrm{B}}=$ Response to other test gases.

Larger value of ' $\mathrm{K}$ ' for target gas signifies that the sensor has excellent proficiency to discriminate target gas from the assortment of gases [38, 39]. Plot of response $v s$. time for NiO film upon 5000 ppm exposure of LPG is shown in Fig. 5(c). SILAR-deposited NiO film demonstrated a response of $72 \%$ to $5000 \mathrm{ppm}$ exposure of LPG with fast response (94 s) and recovery time $(92 \mathrm{~s})$. The porous morphology of $\mathrm{NiO}$ as visualized by FESEM could provide a high surface area to interact LPG molecules resulting in better response. It was observed that upon interaction of LPG gas with $\mathrm{NiO}$ film, resistance of sensing film increased drastically at the beginning and continued to increase gradually before attaining a constant value. Recovery of sensor was achieved by opening the outlet of the test chamber. The variation of response with different LPG concentration for NiO film is illustrated in Fig. 5(d). It was observed that with increase in concentration of LPG from 100 to $5000 \mathrm{ppm}$, the response increased gradually and above $5000 \mathrm{ppm}$ concentration, sensor presented a stable response of $72 \%$. The plot of response for different LPG concentrations for $\mathrm{NiO}$ sensor film is shown in Fig. 5 (d). The low gas concentration implies a lower surface coverage, resulting in a lower surface reaction between the adsorbed oxygen species at surface of film and the gas molecules, hence lower response was observed. Furthermore, the higher response can be attributed to the larger surface coverage as a larger surface offers more possibility for reaction between gas molecules and adsorbed oxygen species at the film surface. High response can be expected, if the amount of adsorbed LPG is larger and reaction between the adsorbed LPG and oxygen species is more favorable. But at a certain stage, upon increasing the LPG concentration, the surface reaction does not increase and eventually saturation takes place and sensor exhibits stable response. The repeatability in response of $\mathrm{NiO}$ sensor film was studied (to $5000 \mathrm{ppm} \mathrm{LPG)}$ ) and the equivalent results are presented in Fig. 5 (e), which demonstrates a relatively equivalent response to all the LPG exposures. For the practical application of gas sensors; stability is one of the decisive parameters. Stability measurements of the $\mathrm{NiO}$ sensor film towards $5000 \mathrm{ppm}$ exposure of LPG for 30 days 
at an interval of 5 days were carried out and displayed in Fig. 5 (f). Initially, NiO sensor film approved a good response of $72 \%$, while it dropped to $66 \%$ after 30 days with excellent stability of $91 \%$. It is familiar that, the general disadvantage of inorganic material based gas sensors is its shrinkage in response value due to the aging induced effects [40]. Based on the gas sensing results, it was concluded that the SILAR-deposited $\mathrm{NiO}$ was potential candidate for detecting LPG at lower temperature.

\subsection{LPG sensing mechanism}

It is eminent that the sensing mechanism of metal oxide semiconductor-based gas sensors is primarily based on a change in the electrical resistance owing to gas adsorption and desorption on the surface of the sensor film. It was observed that upon exposure to LPG gas molecules SILAR-deposited $\mathrm{NiO}$ sensor film revealed abrupt increase in its resistance value. Here, the sensing mechanism of $\mathrm{NiO}$ with LPG gas was enlightened through the potential barrier model [Fig. 6]. When the sensing material (herein $\mathrm{NiO}$ ) is exposed to air, it naturally adsorbs oxygen from air. Adsorbed oxygen on the surface of the film is temperature dependent. Oxygen could adsorb on metal oxide surface i.e. NiO through following ways [41]:

$$
\begin{aligned}
& \mathrm{O}_{2}(\text { air }) \quad \mathrm{O}_{2}(\text { ads }) \\
& \mathrm{O}_{2}(\text { ads })+\mathrm{e}^{-} \longrightarrow \mathrm{O}_{2}^{-}(\text {ads }) \\
& \mathrm{O}_{2}^{-}(\mathrm{ads})+\mathrm{e}^{-} \longrightarrow 2 \mathrm{O}^{-}(\mathrm{ads}) \\
& \mathrm{O}^{-}(\mathrm{ads})+\mathrm{e}^{-} \longrightarrow \mathrm{O}^{2-}(\mathrm{ads})
\end{aligned}
$$

Below $100{ }^{\circ} \mathrm{C}$, it has $\mathrm{O}_{2}{ }^{-}$nature, in between $100-300{ }^{\circ} \mathrm{C}$ having $\mathrm{O}^{-}$character and above $300{ }^{\circ} \mathrm{C}$, it has $\mathrm{O}_{2}^{-}$nature [42]. In present case, $\mathrm{O}^{-}$was more reactive because optimized temperature of $\mathrm{NiO}$ sensor was $180^{\circ} \mathrm{C}$. The adsorbed oxygen at grain boundary might trap electrons from the $\mathrm{NiO}$ by forming a barrier for electron transport [Fig. 6]. After interacting reducing LPG gas (electron donating in nature) molecules with $p$-type $\mathrm{NiO}$ electrons to the valence band of $\mathrm{NiO}$ were dominant, hence the conductivity was decreased, resulting in increased resistance value. Sudden increase in the resistance value on exposure to LPG is ascribed to an increase in the height of potential barrier [43]. As the sensor exposed to air, LPG gas molecules was removed and recovery of sensor was achieved. 


\section{Conclusions}

In summary, we have investigated gas sensing properties of SILAR-deposited NiO films towards various oxidizing and reducing gases with respect to temperature. Structure, morphology and phase purity studies are initially screened and then applied in gas sensor studied by employing various oxidizing and reducing gases. Gas sensing results corroborated that the $\mathrm{NiO}$ sensor film was quite sensitive and selective towards LPG gas at operating temperature of $180{ }^{\circ} \mathrm{C}$. $\mathrm{NiO}$ sensor film exhibited fast response time of $94 \mathrm{~s}$ and short recovery time of $92 \mathrm{~s}$ with a good response of $72 \%$ upon $5000 \mathrm{ppm}$ exposure of LPG. Furthermore, NiO sensor is able to detect LPG concentration as low as $100 \mathrm{ppm}$ concentration with response of $10 \%$, which suggesting its potential in discriminating detection of LPG among a variety of gases.

\section{Acknowledgements}

We, contributing authors, dedicate this work to Late Prof. Ashod D. Sagar, Former Director, School of Chemical Sciences, SRTM, University, Nanded, India. The authors extend their appreciation to the International Scientific Partnership Program ISPP at King Saud University for funding this research work through ISPP\# 0032. FJS would like to thank the National Science Foundation of China (21574086), Nanshan District Key Lab for Biopolymers and Safety Evaluation (No. KC2014ZDZJ0001A), and Shenzhen City High Level Talent Program and Shenzhen Sci \& Tech research grant (ZDSYS201507141105130, JCYJ20140509172719311). 


\section{References}

[1] J. Lee, M. C. Orilall, S. C. Warren, M. Kamperman, F. J. Disalvo, U. Wiesner, Direct access

to thermally stable and highly crystalline mesoporous transition-metal oxides with uniform pores, Nat. Mater., 7 (2008) 222-8.

[2] S.T. Navale, D. K. Bandgar, S. R. Nalage, G. D. Khuspe, M. A. Chougule, Y. D. Kolekar, Shashwati Sen, V. B. Patil, Synthesis of $\mathrm{Fe}_{2} \mathrm{O}_{3}$ nanoparticles for nitrogen dioxide gas sensing applications, Cera. Inter., 39 (2013) 6453-6460.

[3] M. M. Kotarski, and J. M. Smulko, Hazardous gases detection by fluctuation-enhanced gas sensing, Fluctuation and Noise Letters, 9 (04) (2010), 359-371.

[4] I. Alessandri, E. Comini, E. Bontempi, G. Faglia, L. E. Depero, G. Sberveglieri, Cr-inserted $\mathrm{TiO}_{2}$ thin films for chemical gas sensors, Sens. Actua. B Chem., 128 (2007) 312-319.

[5] J. Hotovy, L. Huran, S. Spicess, S. Hascik, V. Rehacek, Preparation of nickel oxide thin films for gas sensors applications, Sens. Actu. B: Chem., 57 (1999)147-152.

[6] C. Feldman, H. O. Jungk, Polyol-mrdiated synthesis of nanoscale oxide particles, Angew. Chem., 40 (2001) 359-362.

[7] D. Tao, F. Wei, New procedure towards size-homogeneous and well-dispersed nickel oxide nanoparticles of $30 \mathrm{~nm}$, Mater. Lett., 58 (2004) 3226-3228.

[8] F. Reinert, P. Steiner, H. Hufner, J. Schmitt, M. Fink, Knupfer, P. Sandal, E. Z. Bertel, Electron and hole doping in NiO, Phys. B, 97 (1995) 83-93.

[9] V. V. Jadhav, D. V. Shinde, S. A. Patil, S. Liu, S. U. Mutkule, M. Naushad, R. S. Mane,

K. N. Hui, S. H. Han, Morphology-inspired low-temperature liquefied petroleum gas sensors of indium oxide, Scripta Materialia, 107 (2015) 54-58.

[10] L. Liu, M. Anderson, Porous nickel oxide/nickel films for electrochemical capacitors, J. Electrochem. Soc., 143 (1996) 124-130.

[11] V. Srinivasan, J. Weidner, An electrochemical route for making porous nickel oxide electrochemical capacitors, J. Electrochem. Soc., 144 (1997) 210-213.

[12] H. Y. Ryu, G. P. Choi, W. S. Lee, W. S. Park, Preferred orientations of NiO thin films prepared by RF magnetron sputtering, J. Matter. Sci. Lett., 39 (2004) 4375-4377. 
[13] H. Sato, T. Minami, S. Takata, T. Yamada, Transparent conducting $p$-type NiO thin films prepared by magnetron sputtering, Thin Solid Films, 236 (1993) 27-31.

[14] J. S. White, M. Bator, Y. Hu, H. Luetkens, J. Stahn, S. Capelli, S. Das, M. Dobeli, T. Lippert, V. K. Malik, J. Martynczuk, A. Wokaun, M. Kenzelmann, C. Niedermayer, C. W. Schneider, Strain-induced ferromagnetism in antiferromagnetic $\mathrm{LuMnO}_{3}$ thin films, Phys. Rev. Lett., 111 (2013) 037201.

[15] S. R. Krishnakumar, M. Liberati, C. Grazioli, M. Veronese, S. Turchini, P. Luches, S. Valeri, C. Carbone, Magnetic linear dichroism studies of in situ grown NiO thin films, J. Magn. Magn. Mater., 310 (2007) 8-12.

[16] J. He, H. Lindstrom, A. Hagfeldt, S. E. Lindquist, Dye sensitized nanostrucured $p$-type nickel oxide film as a photocathode solar cell, J. Phys. Chem. B., 103 (1999) 8940-8943.

[17] K. C. Liu, M. A. Anderson, Porous nickel oxide/nickel films for electrochemical capacitors, J. Electro. Soc., 143 (1996)124-130.

[18] Y. D. Wang, C. L. Ma, X. D. Sun, H. D. Li, Preparation of nanocrystalline metal oxide powders with the surfactant-meditated method, Inorg. Chem. Commun., 5 (2002) 751-755.

[19] S. Deki, H. Yanagimito, S. Hiraoka, $\mathrm{NH}_{2}$-terminated poly(ethylene oxide) containing nanosized NiO particles: synthesis, characterization, and structural considerations, Chem. Mater., 15 (2003) 4916-4922.

[20] S. T. Navale, V. V. Mali, S. A. Pawar, R. S. Mane, M. Naushad, F. J. Stadler, V. B. Patil, Electrochemical supercapacitor development based on electrodeposited nickel oxide film, RSC Adv., 5 (2015) 51961-51965.

[21] L. Xiang, X. Y. Deng, Y. Jin, Experimental study on synthesis of NiO nanoparticles, Scripta Mater., 47 (2002) 219-224.

[22] M. Krunks, J. Soon, T. Unt, A. Mere, V. Mikli, Deposition of p-type NiO films by chemical spray pyrolysis, Vacuum, 107 (2014) 242-246.

[23] A. Agrawal, H. R. Habibi, R. K. Agrawal, J. P. Cronin, D. M. Roberts, R. Caron-Popowich, C. M. Lampert, Effect of deposition pressure on the microstructure and electrochromic properties of electron-beam-evaporated nickel oxide films, Thin Solid Films, 221 (1992) 239-253.

[24] D. Wruck, M. Rubin, Structure and electronic properties of electrochromic NiO films, J. Electrochem. Soc., 140 (1993)1097-1104. 
[25] S. Yamada, T. Yoshuoka, M. Miyashita, K.Urabe, M. Kiato, Electrochromic properties of sputtered nickel-oxide films, J. Appl. Phys., 63 (1988) 2116-2119.

[26] K. Yoshimura, M. T. Tanemura, Nickel oxide electrochromic thin films prepared by reactive DC magnetron sputtering, J. Appl. Phys., 34 (1995) 2440.

[27] S. B. Kulkarni, V. S. Jamdade, D. S. Dhawale, C. D. Lokhande, Synthesis and characterization of $\beta-\mathrm{Ni}(\mathrm{OH})_{2}$ up grown nanoflakes by SILAR method, Appl. Surf. Sci., 225 (2009) 8390-8394.

[28] C. Yuan, X. Zhang, L. Su, B. Gao, L. Shen, Facile synthesis and self-assembly of hierarchical porous $\mathrm{NiO}$ nano/micro spherical superstructures for high performance supercapacitors, J. Mater. Chem., 19 (2009) 5772-5777.

[29] A. Surca, B. Orel, B. Pihlr, P. Bukovec, Optical, spectroelectrochemical and structural properties of sol-gel derived Ni-oxide electrochromic film, J. Electroanal. Chem., 408 (1996) 83-100.

[30] J. L. Gunjakar, A. M. More, C. D. Lokhande, Chemical deposition of nanocrystalline nickel oxide from urea containing bath and its use in liquefied petroleum gas sensor, Sens. Actu. B: Chem., 131 (2008) 356-361.

[31] S. R. Nalage, M. A. Chougule, S. Sen, V. B. Patil, Novel method for fabrication of $\mathrm{NiO}$ sensor for $\mathrm{NO}_{2}$ monitoring, J. Mater Sci: Mater. Electron., 24 (2013) 368-375.

[32] D. S. Dalavi, N. S. Harale, I.S. Mulla, V. K. Rao, V. B. Patil, I. Y. Kim, J. H. Kim, P. S. Patil, Nanoporous network of nickel oxide for ammonia gas detection, Mater. Lett., 146 (2015) 103-107.

[33] A. Kumar, A. Saxena, A. De, R. Shankar, S. Mozumdar, Controlled synthesis of sizetunable nickel and nickel oxide nanoparticles using water-in-oil microemulsions, Adv. Nat. Sci: Nanosci. Nanotech., 4 (2013) 025009.

[34] J. Fu, C. Zhao, J. Zhang, Y. Peng, E. Xie, Enhanced gas sensing performance of electrospun Pt-functionalized $\mathrm{NiO}$ nanotubes with chemical and electronic sensitization, ACS Appl. Mater. Inter., 5 (2013) 7410-7416.

[35] S. T. Navale, D. K. Bandgar, S. R. Nalage, R. N. Mulik, S. A. Pawar, M. A. Chougule, V. B. Patil, Novel process for synthesis of $\alpha-\mathrm{Fe}_{2} \mathrm{O}_{3}$ : microstructural and optoelectronic investigations, J Mater Sci: Mater Elec., 24 (2013) 1422-1430. 
[36] C. Luo, D. Li, W. Wu, Y. Zhang, C. Pan, C, Preparation of porous micro-nano-structure $\mathrm{NiO} / \mathrm{ZnO}$ heterojunction and its photocatalytic property, RSC Adv., 4 (2014) 3090-3095.

[37] N. M. Ulmane, A. Kuzmin, J. Grabis, I. Sildos, V. I. Voronin, I. F. Berger, V. A. Kazantse, Structural and magnetic properties of nickel oxide nanopowders, Solid State Phenomena, 168 (2011) 341-344.

[38] S. T. Navale, A. T. Mane, M. A. Chougule, R. D. Sakhare, S. R. Nalage, V. B. Patil, Highly selective and sensitive room temperature $\mathrm{NO}_{2}$ gas sensor based on polypyrrole thin films, Synth. Met., 189 (2014) 94-99.

[39] S. T. Navale, M. A. Chougule, A. T. Mane, V. B. Patil, Highly sensitive, reproducible, selective and stable CSA-polypyrrole $\mathrm{NO}_{2}$ sensor, Synth. Met., 189 (2014) 111-118.

[40] S. T. Navale, A. T. Mane, M. A. Chougule, N. M. Shinde, JunHo Kim, V. B. Patil, Highly selective and sensitive $\mathrm{CdS}$ thin film sensors for detection of $\mathrm{NO}_{2}$ gas, RSC Adv., 4 (2014), 44547-44554.

[41] H. J. Xia, Y. Wang, F. H. Kong, S. K. Wang, B. L. Zhu, X. Z. Guo, J. Zhang, Y. M. Wang, S. H. Wu, Au-doped $\mathrm{WO}_{3}$-based sensor for $\mathrm{NO}_{2}$ detection at low operating temperature, Sens. Actua. B Chem., 134 (2008) 133-139.

[42] S.T. Navale, V.V. Jadhav, K.K. Tehare, R.U.R. Sagar, C.S. Biswas, M. Galluzzi, W. Liang, V.B. Patil, R.S. Mane, F.J. Stadler, Solid-state synthesis strategy of ZnO nanoparticles for the rapid detection of hazardous $\mathrm{Cl}_{2}$, Sens. Actua. B Chem., 238 (2017) 1102-1110

[43] S. Chaisitsak, Nanocrystalline $\mathrm{SnO}_{2}$ : F thin films for liquid petroleum gas sensors, Sensors, 11 (2011) 7127-7140. 


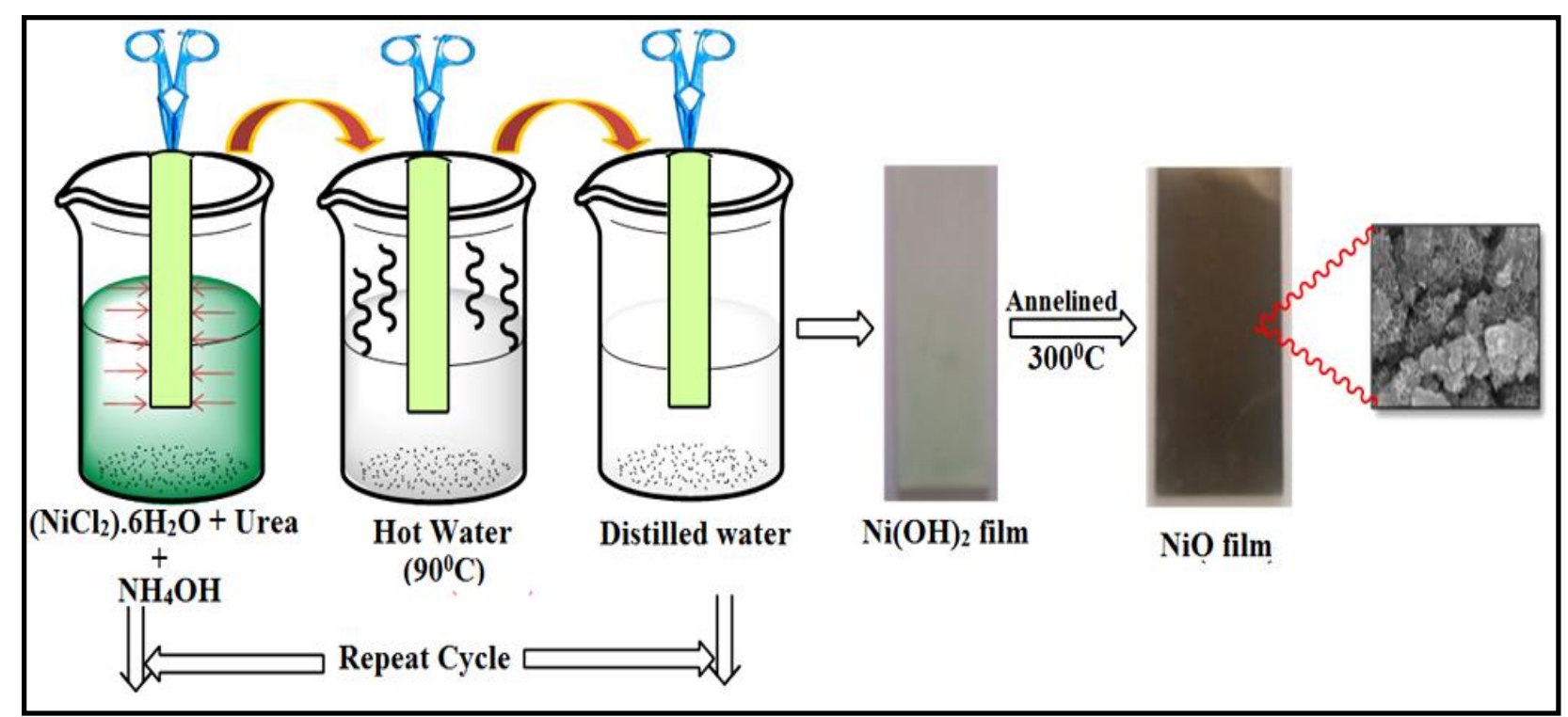

Fig.1: Schematic representation of the formation of $\mathrm{NiO}$ film. 

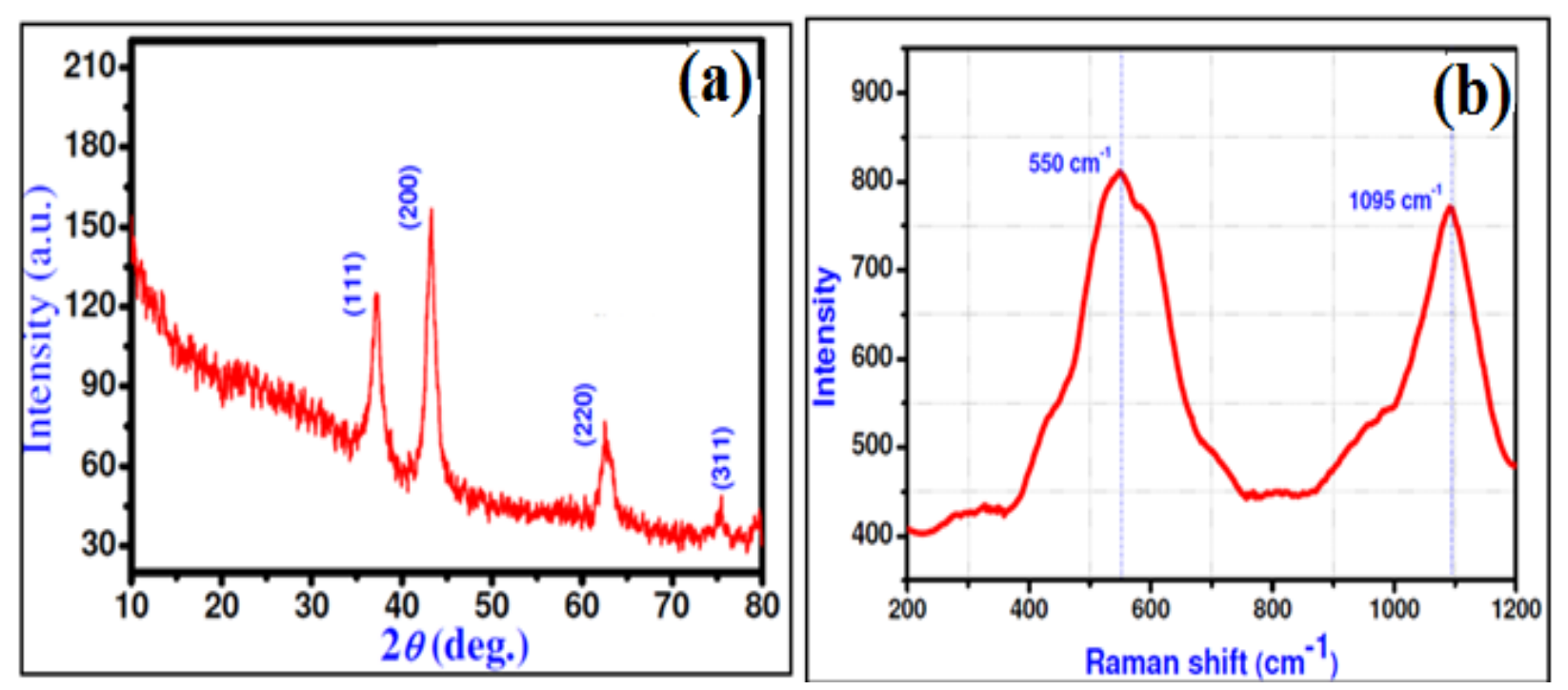

Fig.2: (a) XRD, and (b) Raman spectrum NiO film. 

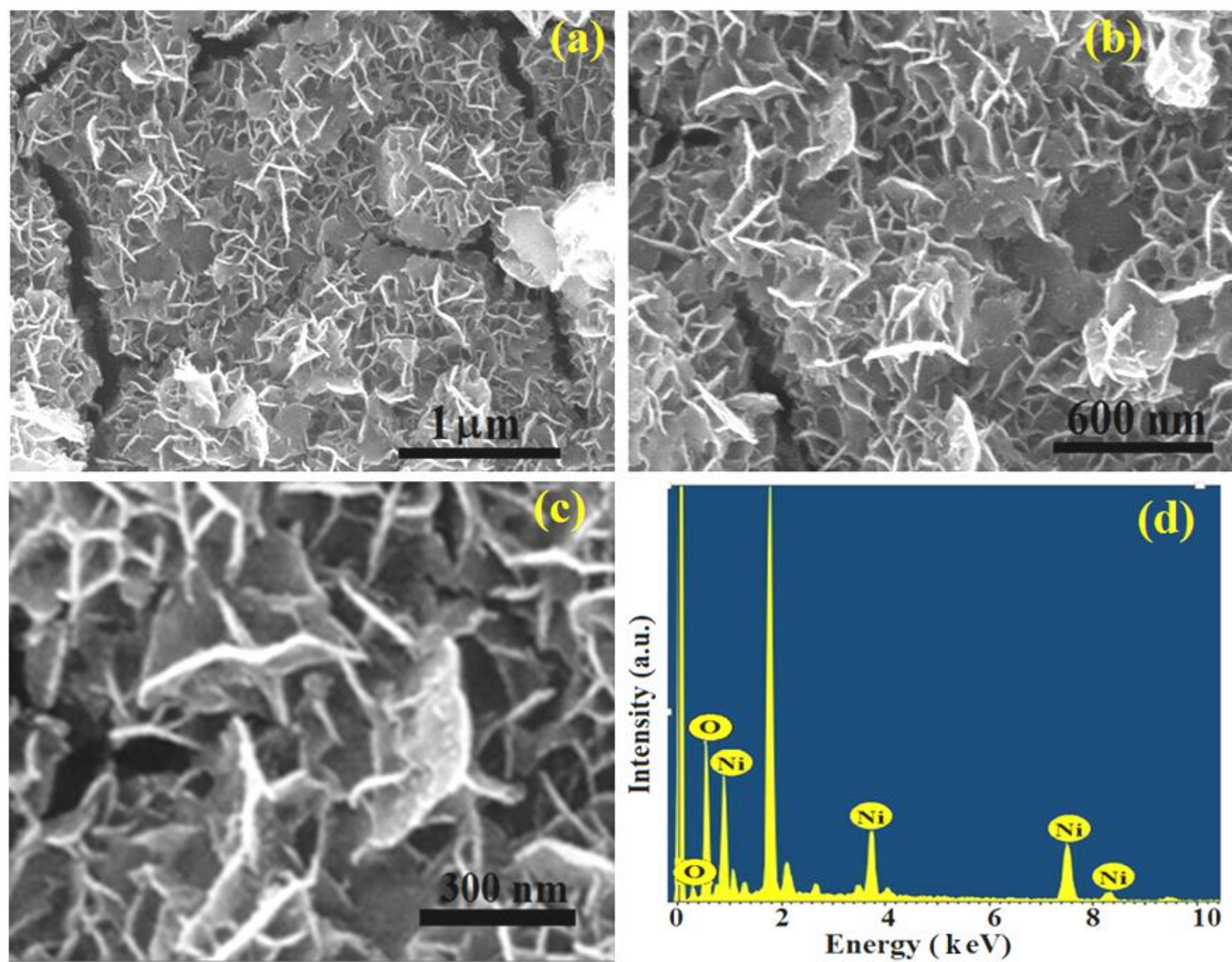

Fig.3: (a, b, c) FESEM images at different magnifications, and (d) elemental composition mapping analysis of $\mathrm{NiO}$ film. 


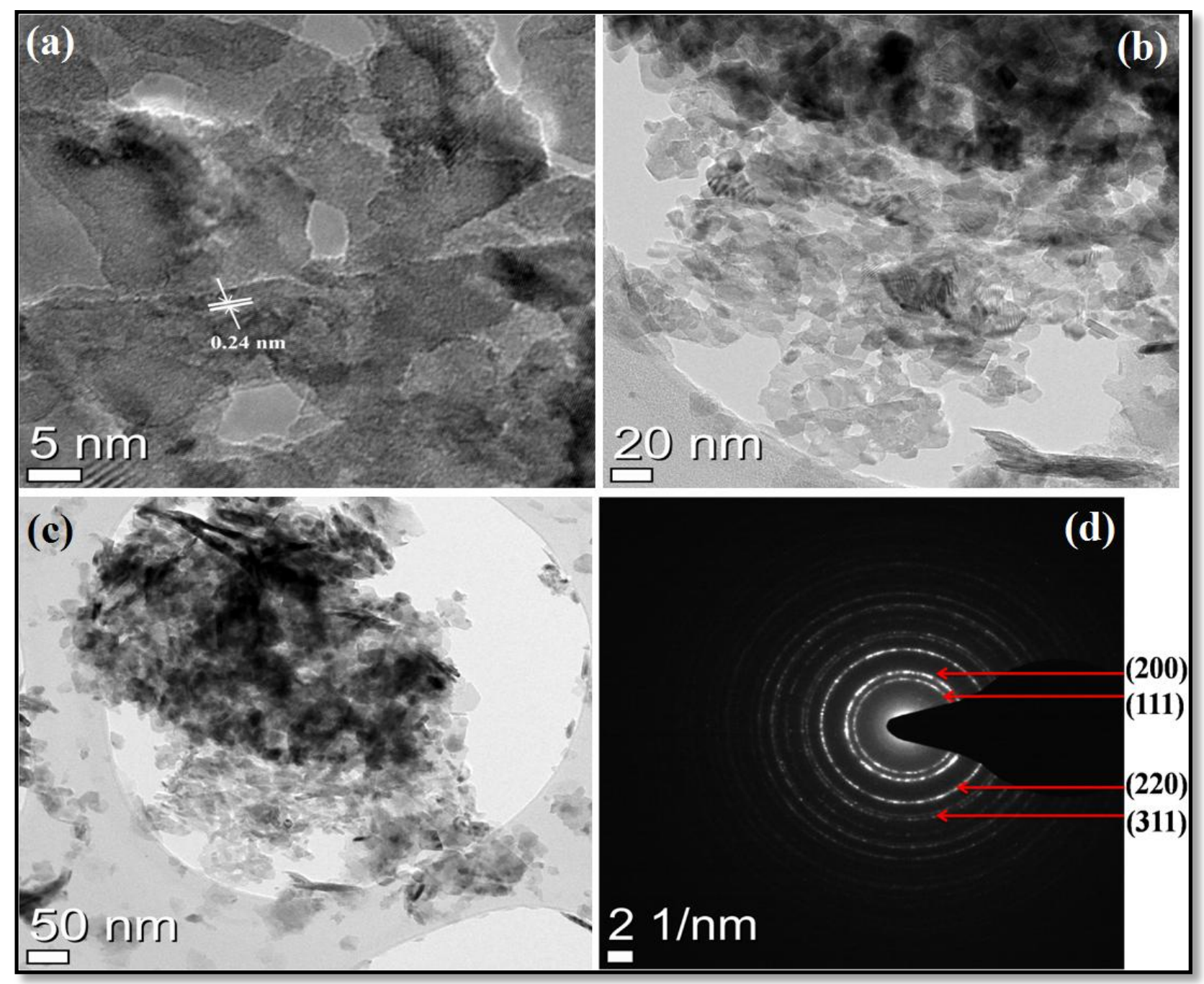

Fig.4: (a) HRTEM, (b, c) TEM images at two different magnifications, and (d) SAED pattern of $\mathrm{NiO}$. 

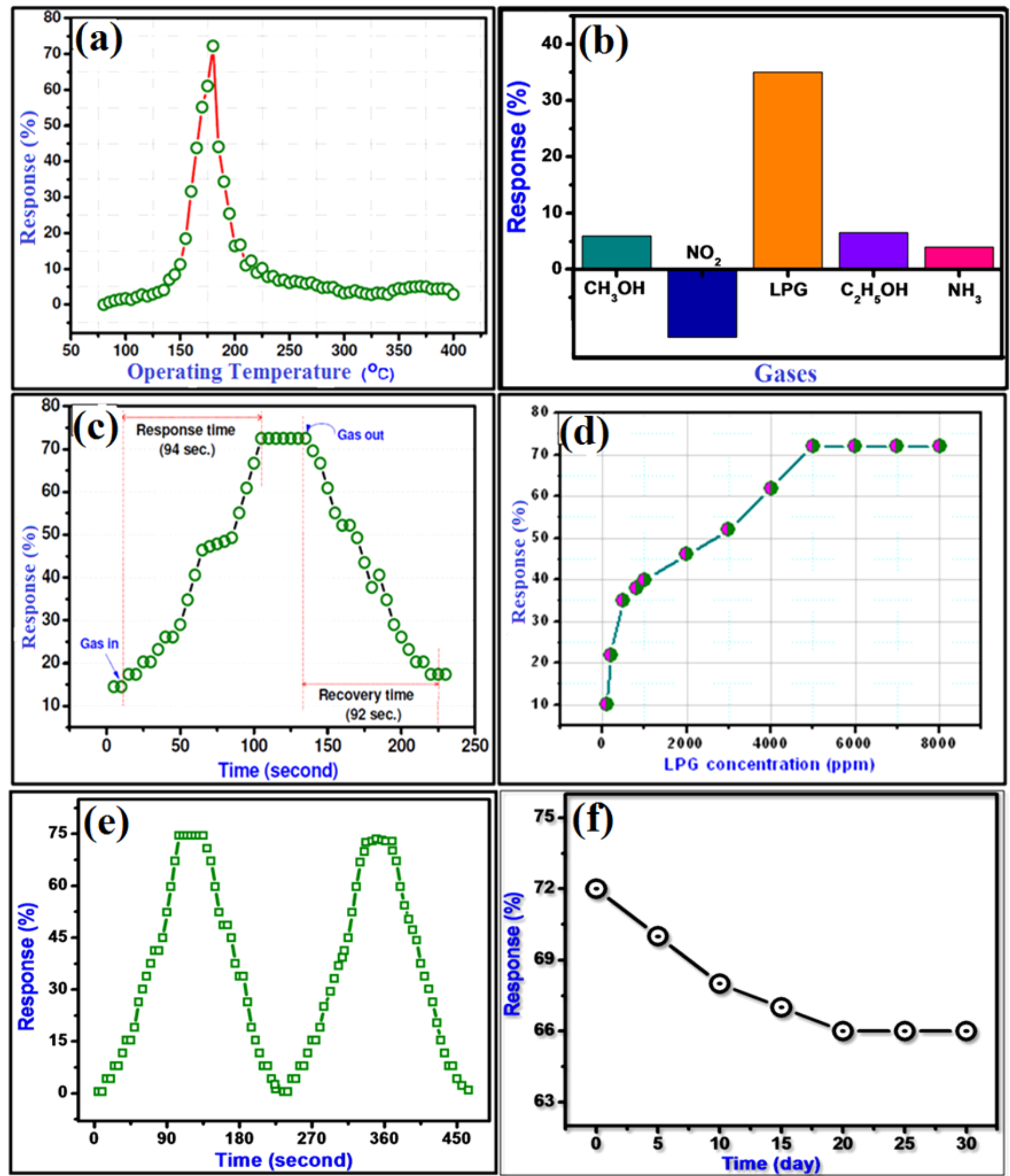

Fig.5: (a) Temperature-dependent response, (b) selectivity study, (c) plot of response as function of time for $5000 \mathrm{ppm}$ LPG, (d) plot of response as a function of different LPG concentration, (e) reproducibility, and (f) stability study of $\mathrm{NiO}$ film. 


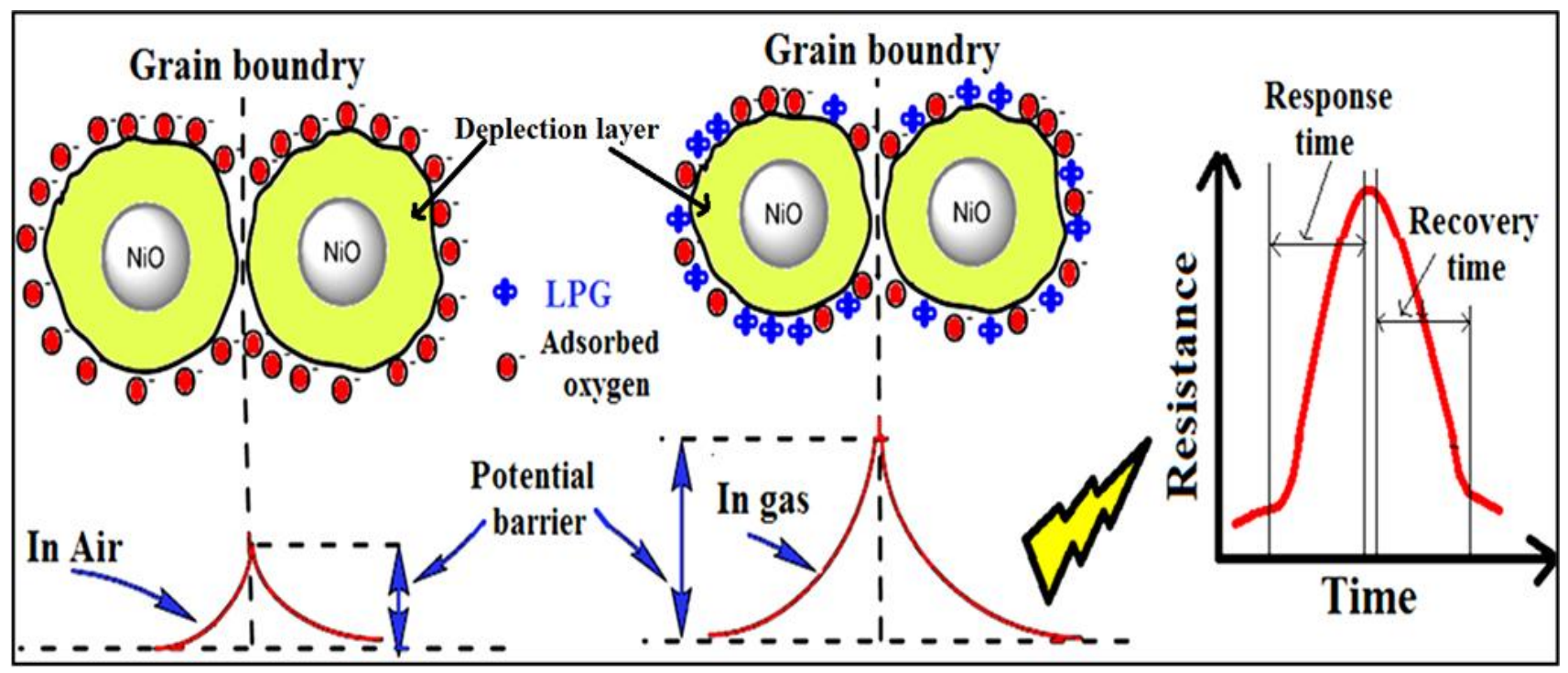

Fig.6: Proposed schematic of interaction of LPG molecules with NiO nanaoplates (here Nanoplates are considered as spherical nanocrystallites). 
Table 1: 'K' values of NiO sensor for LPG (500 ppm) as target gas.

\begin{tabular}{l|l|l|l|l}
\hline Gas & $\mathrm{NH}_{3}$ & $\mathrm{C}_{2} \mathrm{H}_{5} \mathrm{OH}$ & $\mathrm{CH}_{3} \mathrm{OH}$ & $\mathrm{NO}_{2}$ \\
\hline ' $\mathrm{K}$ ' value & 8.75 & 5.35 & 5.83 & 2.91 \\
\hline
\end{tabular}




\section{Graphical abstract}

\section{Solution-processed Nickel Oxide films and their Liquefied Petroleum Gas Sensing Activity}

Sandesh U. Mutkule, Sachin T. Navale, V. V. Jadhav, Swapnil B. Ambade, Mu. Naushad, Ashok D. Sagar, Vikas B. Patil, Florian J. Stadler, and Rajaram S. Mane

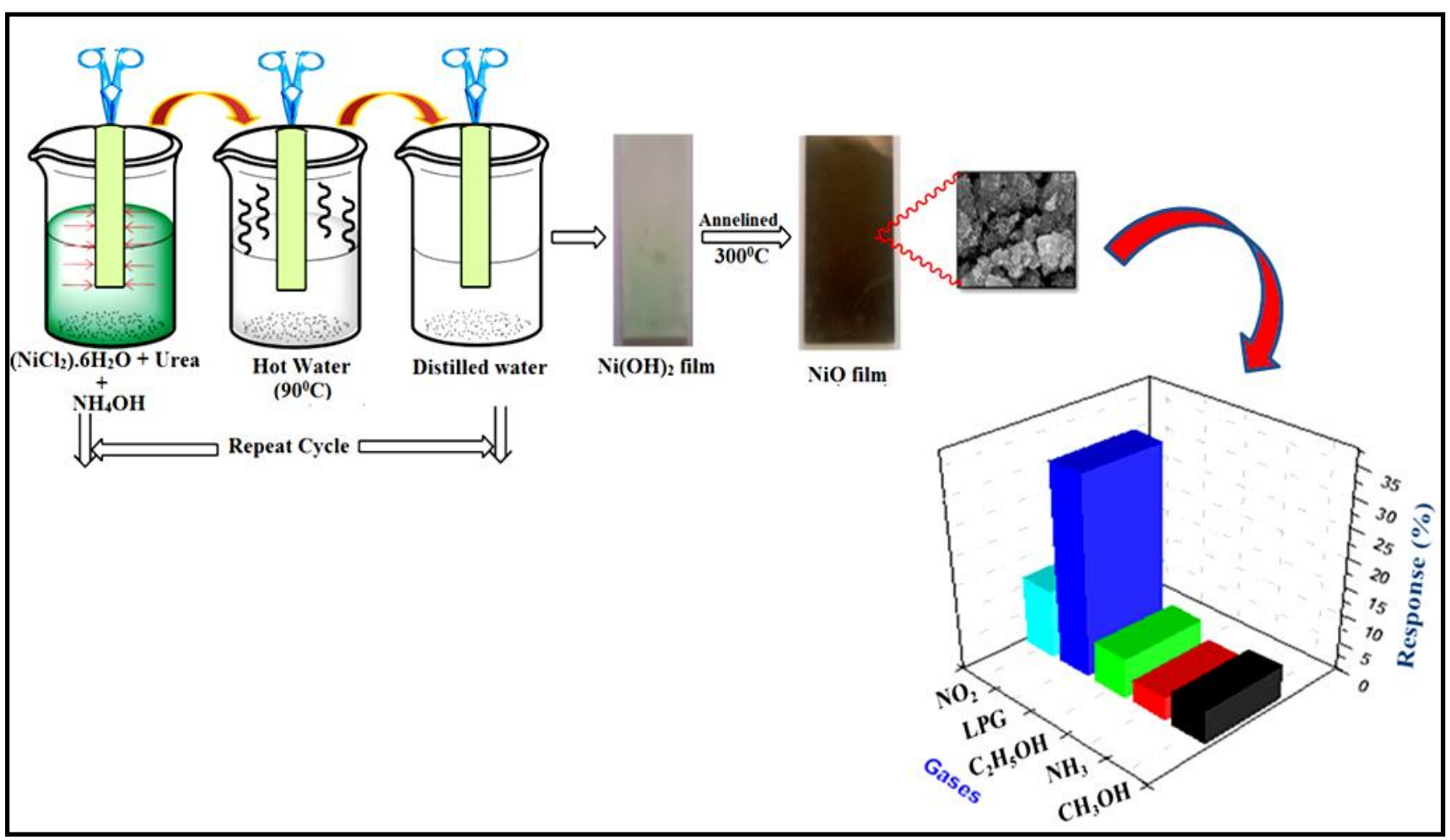

